
SOBRE DIREITOS HUMANOS NOS CASOS ENVOLVENDO O DIREITO

AO ACESSO À MACONHA MEDICINAL: UM ESTUDO A PARTIR DAS DEMANDAS JUDICIAIS ENVOLVENDO DERIVADOS DE CANNABIS NA

\title{
UMA ANÁLISE DA APLICAÇÃO DOS TRATADOS E CONVENÇÕES SOBRE DIREITOS HUMANOS NOS CASOS ENVOLVENDO O DIREITO AO ACESSO À MACONHA MEDICINAL: UM ESTUDO A PARTIR DAS DEMANDAS JUDICIAIS ENVOLVENDO DERIVADOS DE CANNABIS NA PARAÍBA
}

\author{
AN ANALYSIS OF THE APPLICATION OF HUMAN RIGHTS TREATIES AND \\ CONVENTIONS IN CASES INVOLVING THE RIGHT TO ACCESS MEDICAL \\ MARIJUANA: A STUDY OF LAWSUITS INVOLVING CANNABIS DERIVATIVES IN
} PARAÍBA

\section{UN ANÁLISIS DE LA APLICACIÓN DE LOS TRATADOS Y CONVENCIONES DE DERECHOS HUMANOS EN CASOS QUE INVOLUCRAN EL DERECHO DE ACCESO A LA MARIHUANA MEDICINAL: UN ESTUDIO DE DEMANDAS QUE INVOLUCRAN DERIVADOS DE CANNABIS EN PARAÍBA}

\author{
LUCIANO NASCIMENTO SILVA \\ https://orcid.org/0000-0002-9380-9292 / http:/ / lattes.cnpq.br/7904935639605967 / \\ lucianonascimento@hotmail.com \\ Universidade Federal da Paraíba - UFPB \\ João Pessoa, PB, Brasil
}

LUCAS LOPES OLIVEIRA

https://orcid.org/0000-0001-5925-7693 / http://lattes.cnpq.br/4938979323766615 / lucasoliveira.sol74@gmail.com Universidade Federal da Paraíba - UFPB

João Pessoa, PB, Brasil

\section{RESUMO}

A problemática do direito ao acesso a remédios à base de cannabis sativa tem desafiado os cenários acadêmicos e os espaços de poder. Essa demanda legítima constitui um imperativo e se liga à efetividade dos Direitos Humanos. Trabalha-se com a hipótese de que a proibição ou a criação de dificuldades burocráticas por parte do Estado para o acesso à maconha a quem dela precise para fins medicinais/terapêuticos constitui violação dos termos dos Tratados Internacionais de Direitos Humanos dos quais o Brasil faz parte. O artigo objetiva de modo geral um estudo sistemático e crítico dessa problemática à luz das construções interpretativas sobre o Sistema Internacional de Proteção dos Direitos Humanos. Para tanto, realiza-se uma pesquisa sociojurídica, exploratória, bibliográfica e documental. Como pesquisa documental, escolhe-se a atuação do Ministério Público Federal da Paraíba na defesa dos direitos de pacientes para pensar como as categorias jurídicas dos Tratados e Convenções Internacionais são mobilizadas nesse processo.

Palavras-Chave: Direito à saúde; Direito humanos; Maconha medicinal; Tratados e Convenções Internacionais.

\section{ABSTRACT}

The problem of the right to access to remedies made of cannabis sativa has challenged the academic scenarios and spaces of power. This legitimate demand constitutes an imperative and is linked to the effectiveness of Human Rights. We work with the hypothesis that the prohibition or the creation of bureaucratic difficulties by the State in order to 
UMA ANÁLISE DA APLICAÇÃO DOS TRATADOS E CONVENÇÕES SOBRE DIREITOS HUMANOS NOS CASOS ENVOLVENDO O DIREITO

AO ACESSO À MACONHA MEDICINAL: UM ESTUDO A PARTIR DAS DEMANDAS JUDICIAIS ENVOLVENDO DERIVADOS DE CANNABIS NA

PARAÍBA

LUCIANO NASCIMENTO SILVA LUCAS LOPES OLIVEIRA

access marijuana by who need it for medicinal or therapeutic purposes violates the terms of the International Agreements of Human Rights, which Brazil is part of. The article aims at a systematic and critical study of this problem in the light of interpretative constructions on the International System for the Protection of Human Rights. For this purpose, we will carry out an exploratory socio-juridical bibliographical and documentary research. As documentary research we will choose the action of the Public Ministry of Paraíba in the defense of patients' rights to think about how the legal categories of the International Agreements and Conventions are mobilized in this process.

Keywords: Right to health; Human rights; Medicinal marijuana; International Agreements and Conventions.

\section{RESUMEN}

La problemática del derecho al acceso a los medicamentos a base de cannabis sativa ha desafiado los escenarios académicos y los espacios de poder. Esta demanda legítima constituye un imperativo y se vincula a la efectividad de los derechos humanos. Trabajamos con la hipótesis de que la prohibición o la creación de dificultades burocráticas por parte del Estado para el acceso a la marihuana a quien la necesite para fines medicinales o terapéuticos constituye violación de los términos de los Tratados Internacionales de Derechos Humanos de los cuales Brasil forma parte. El artículo objetiva de modo general un estudio sistemático y crítico de esta problemática a la luz de las construcciones interpretativas sobre el Sistema Internacional de Protección de los Derechos Humanos. Para ello realizaremos una investigación sociojurídica exploratoria, bibliográfica y documental. Como investigación documental elegiremos la actuación del Ministerio Público Federal de Paraíba en la defensa de los derechos de pacientes para pensar cómo las categorías jurídicas de los Tratados y Convenciones Internacionales son movilizadas en este proceso.

Palabras clave: Derecho a la salud. Derechos humanos. Marihuana medicinal. Tratados y convenciones Internacionales.

\section{SUMÁRIO}

INTRODUÇÃO; 1 A SAÚDE ENQUANTO DIREITO HUMANO; 2 A PROBLEMÁTICA DO USO DA MACONHA MEDICINAL: UMA ANÁLISE A PARTIR DOS TRATADOS SOBRE DIREITOS HUMANOS; 3 ANÁLISE DA ATUAÇÃO DO MPF-PB NA DEFESA DOS DIREITOS DOS PACIENTES DE MACONHA MEDICINAL E OS MARCOS LEGAIS INTERNACIONAIS DE DIREITOS HUMANOS; CONCLUSÃO; REFERÊNCIAS.

\section{INTRODUÇÃO}

O direito ao acesso à maconha medicinal tem sido amplamente discutido no Brasil. A intensa militância de pacientes, familiares de pacientes e de associações conseguiu importantes vitórias tanto judiciais quanto culturais. Apesar disso, ainda paira grande insegurança jurídica para aquele que optou por usar derivados de maconha em seu tratamento médico ou terapêutico. Tal fato se deve à criminalização da maconha que abre margem para que um paciente ou seu familiar que use ou plante maconha para fins medicinais possam ser enquadrados nos tipos penais da Lei de Drogas. Logo, faz-se necessária uma revisão na política de drogas de forma a afastar essa insegurança jurídica, descriminalizando e regulamentando o uso da cannabis para fins medicinais.

Mas, enquanto esse processo político-institucional não se efetua a partir de um processo mais amplo, não se pode olvidar que dentro do próprio ordenamento jurídico brasileiro existem 
ISSN 1981-3694

(DOI): $10.5902 / 1981369437744$

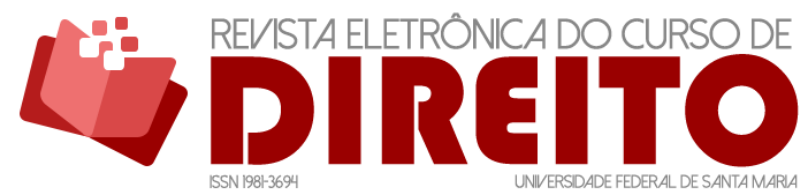

UMA ANÁLISE DA APLICAÇÃO DOS TRATADOS E CONVENÇÕES SOBRE DIREITOS HUMANOS NOS CASOS ENVOLVENDO O DIREITO

AO ACESSO À MACONHA MEDICINAL: UM ESTUDO A PARTIR DAS DEMANDAS JUDICIAIS ENVOLVENDO DERIVADOS DE CANNABIS NA

PARAÍBA

LUCIANO NASCIMENTO SILVA LUCAS LOPES OLIVEIRA

dispositivos que garantem o direito à saúde de pacientes que demandam acesso a derivados de cannabis e que impedem qualquer forma de obstaculização desse direito por parte do Estado. Assim, com base nesses imperativos, exige-se uma conduta negativa, de modo a não impedir que as pessoas exerçam a autonomia e o direito à saúde quando optam por utilizar remédios à base de derivados da cannabis. Também, exige-se uma conduta positiva no sentido de criação de políticas públicas e de prestação de serviços públicos, de modo a atender essa parcela dos usuários do SUS que demandam acesso à cannabis e seus derivados.

Esses dispositivos acima mencionados podem ser achados em vários documentos, mas restringe-se a análise apenas aos Tratados e Convenções Internacionais sobre Direitos Humanos assinados e internalizados pelo Brasil. Trabalha-se, portanto, com a hipótese de que as normativas de direitos humanos já permitem o direito ao uso medicinal da maconha, não se podendo interpretar de forma diversa sob pena de minimizar a proteção ao direito humano à saúde.

Também se observa que, apesar disso, em virtude da persistência de normas penais e de ausência de normas regulamentadoras eficientes para garantir esse direito, muitos cidadãos ainda percebem grande insegurança jurídica a exercerem seu direito à saúde. Assim, é necessário, muitas vezes, recorrer ao judiciário para legitimar algo que deveria ser a prática de todos os órgãos do Estado: a garantia e a máxima proteção do direito humano à vida.

Essa pesquisa tem base qualitativa e natureza exploratória ${ }^{1}$. Assim, parte da compreensão mais ampla do direito ao acesso à maconha medicinal para analisar como as normativas sobre direitos humanos permitem o acesso a derivados de cannabis como meio de resguardar o direito humano à saúde. Após uma análise dos documentos que expressam os direitos humanos no Brasil, parte-se para uma análise da aplicação desses dispositivos quando da defesa judicial dos pacientes e familiares por parte do Ministério Público Federal da ParaíbaMPF/PB através da Procuradoria Regional dos Direitos do Cidadão - PRDC.

Para colher os dados documentais analisados nesse artigo, diligenciou-se junto ao Ministério Público Federal da Paraíba de forma a obter dados referentes à sua atuação no processo de defesa dos interesses de pessoas que dependem da cannabis sativa para o seu tratamento, e entrou-se em contato com a PFDC. A partir disso, tendo esses dados em mãos, tratou-se de identificar os momentos nos quais os dispositivos normativos de proteção aos

1 CRESWELL, John. W. Projeto de pesquisa: métodos qualitativo, quantitativo e misto. Porto Alegre: Artmed, 2007. 
ISSN 1981-3694

(DOI): $10.5902 / 1981369437744$

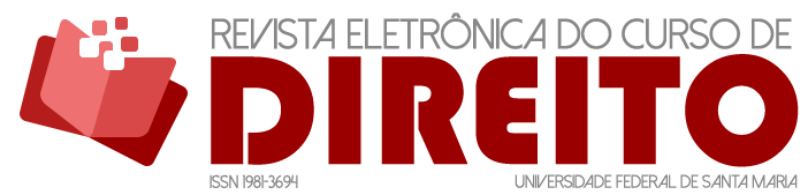

UMA ANÁLISE DA APLICAÇÃO DOS TRATADOS E CONVENÇÕES SOBRE DIREITOS HUMANOS NOS CASOS ENVOLVENDO O DIREITO

AO ACESSO À MACONHA MEDICINAL: UM ESTUDO A PARTIR DAS DEMANDAS JUDICIAIS ENVOLVENDO DERIVADOS DE CANNABIS NA

PARAÍBA

LUCIANO NASCIMENTO SILVA LUCAS LOPES OLIVEIRA

direitos humanos são invocados e seu impacto na argumentação do parquet. A partir dessa coleta de dados, utiliza-se, como estratégia de leitura dos dados documentais colhidos, a estratégia de Análise de Discurso a partir da matriz epistemológica do pensamento de Michel Foucault ${ }^{2}$, tendo em conta as suas observações sobre a estreita relação entre o saber, o poder e o discurso, sendo o discurso expressão de luta e de batalhas que constituem relações de poder móveis e dinâmicas. O presente artigo foi realizado com o apoio da Coordenação de Aperfeiçoamento de Pessoal de Nível Superior - Brasil (CAPES) - Código de Financiamento 001.

No primeiro momento, apresenta-se uma análise do direito à saúde enquanto um direito humano e suas implicações jurídicas. Passa-se, então, para uma análise do direito ao acesso à cannabis medicinal à luz das normas sobre direitos humanos e fundamentais. Ao final, traz-se uma análise da aplicação das normas de direitos humanos em três atuações judiciais do Ministério Público Federal que versavam sobre o acesso à cannabis medicinal no estado da Paraíba.

\section{A SAÚDE ENQUANTO DIREITO HUMANO}

Pensar em direitos humanos, na contemporaneidade, implica em refletir sobre uma importante categoria jurídico-político contemporânea. Os direitos humanos estão positivados e expressos nos Tratados e Convenções Internacionais, nas Constituições nacionais, nas Políticas Públicas e na luta dos movimentos sociais. Essa pluralidade de expressões que envolve a temática dos direitos humanos é o que torna tão complexa a necessidade de analisar tal questão.

Estando positivados pelo Direito, tais direitos se tornam categoria jurídica com expressão de normatividade. Sendo demandados pela sociedade civil, tornam-se uma categoria política. Essa impossibilidade de redução do fenômeno dos direitos humanos a apenas um de seus vieses é o que o torna uma categoria tão importante para o direito contemporâneo. E é justamente essa complexidade que não pode ser negligenciada por qualquer análise que se ponha a investigar alguma dimensão desse fenômeno chamado direitos humanos.

${ }^{2}$ FOUCAULT, Michel. Em defesa da sociedade: curso no Collège de France (1975-1976). São Paulo: Martins Fontes, 1999. 
UMA ANÁLISE DA APLICAÇÃO DOS TRATADOS E CONVENÇÕES SOBRE DIREITOS HUMANOS NOS CASOS ENVOLVENDO O DIREITO

AO ACESSO À MACONHA MEDICINAL: UM ESTUDO A PARTIR DAS DEMANDAS JUDICIAIS ENVOLVENDO DERIVADOS DE CANNABIS NA

PARAÍBA

LUCIANO NASCIMENTO SILVA LUCAS LOPES OLIVEIRA

Isso nos faz refletir que os direitos humanos não devem ser vistos apenas em sua expressão normativa. Esta é a reflexão trazida por Herrera Flores ${ }^{3}$ que lembra da importância dessa categoria nas lutas emancipatórias dos povos. Desse modo, os direitos humanos são frutos de lutas políticas, expressões de embates ou, como prefere o autor, "afirmação da luta do ser humano para ver cumprido seus desejos e necessidades nos contextos vitais em que está situado"4. Dessa forma, é importante olhar o direito para além de sua construção teórica abstrata e legalista e conectá-la a seu sentido político.

Esta complexidade do conceito de direitos humanos nos conduz [...] à formação de uma metodologia relacional para entendê-los, ou seja, a uma forma de compreensão e dotação de sentido aos direitos que reivindiquem a impureza de seus conteúdos, ou, o que é o mesmo, suas estreitas relações com as expectativas e interesses de grupos sociais interessados em sua colocação em prática ${ }^{5}$.

A leitura meramente legalista do fenômeno dos direitos humanos pode ser um obstáculo à melhor compreensão da luta pela dignidade humana. Muitas vezes a retórica de direitos constitui-se como algo esvaziado, haja vista o que, várias vezes, ocorre quando analisa-se preceitos normativos que asseguram direitos, mas que estão apenas no plano abstrato da norma, longe da vida das pessoas.

Dentro do conjunto de direitos humanos reconhecidos no plano internacional, um dos mais importantes é o direito à saúde, um direito humano reconhecido pela Organização das Nações Unidas (ONU), por via da Declaração Universal dos Direitos Humanos - DUDH, aprovada por via da Resolução 217 A III, documento que é um marco do consenso internacional a respeito da proteção da dignidade humana. Esse reconhecimento se dá através do artigo 25 , nos seguintes termos:

Todo ser humano tem direito a um padrão de vida capaz de assegurar a si e à sua família saúde, bem-estar, inclusive alimentação, vestuário, habitação, cuidados médicos e os serviços sociais indispensáveis e direito à segurança em caso de

\footnotetext{
${ }^{3}$ HERRERA, Joaquín Flores. A (re)invenção dos direitos humanos. Florianópolis: Fundação Boiteux, 2009.

${ }^{4}$ HERRERA, Joaquín Flores. A (re)invenção dos direitos humanos. Florianópolis: Fundação Boiteux, 2009. p. 22.

${ }^{5}$ HERRERA, Joaquín Flores. A (re)invenção dos direitos humanos. Florianópolis: Fundação Boiteux, 2009. p. 22.
} 
UMA ANÁLISE DA APLICAÇÃO DOS TRATADOS E CONVENÇÕES SOBRE DIREITOS HUMANOS NOS CASOS ENVOLVENDO O DIREITO

AO ACESSO À MACONHA MEDICINAL: UM ESTUDO A PARTIR DAS DEMANDAS JUDICIAIS ENVOLVENDO DERIVADOS DE CANNABIS NA

PARAÍBA

desemprego, doença, invalidez, viuvez, velhice ou outros casos de perda dos meios de subsistência em circunstâncias fora de seu controle ${ }^{6}$.

É importante lembrar que a DUDH, segundo a tradicional análise do direito internacional, por ser uma declaração, não gozaria de status de direito positivo. Ocorre que, mesmo que não se aceite essa tese, não há como negar o importante caráter de tal declaração, por ser fundante epistemológico de uma nova ordem internacional que teria como base o respeito aos direitos humanos. Pode-se dizer que, apesar de vários outros experimentos que concorreram para a afirmação histórica dos direitos humanos, a concepção atual de direitos humanos que pressupõe o cerne interpretativo dessa categoria advém dessa declaração.

A propósito, as disposições presentes nessa declaração foram repetidas em dois importantes documentos internacionais que trouxeram para o âmbito do direito internacional os dispositivos de proteção aos direitos humanos. Esses documentos seriam o Pacto Internacional sobre Direitos Civis e Políticos e o Pacto Internacional sobre Direitos Econômicos, Sociais e Culturais. Estes dois importantes documentos internacionais trazem em seu corpo direitos que devem ser garantidos por todos os Estados Membros desses acordos.

0 primeiro desses tratados se relaciona ao que Norberto Bobbio ${ }^{7}$ chamou de primeira geração de direitos humanos, que seriam os direitos à liberdade e seus desdobramentos. São direitos frutos do liberalismo político e da busca de limitar o poder do Estado. 0 segundo traria para a proteção internacional os direitos de natureza social, chamados por Bobbio de direitos de segunda geração. Esses direitos, nos quais se encontra presente o direito à saúde, ligam-se às lutas socialistas e sindicais em busca de igualdade, ou seja, são direitos de igualdade que reclamam participação ativa do Estado.

Para trazer à tona essa problemática que se pretende iluminar no presente estudo, é importante que esses dois tratados sejam relevantes para analisar a luta pelo acesso à maconha medicinal. A partir deles, é possível construir uma interpretação dogmática sobre a legitimidade do uso da maconha para fins medicinais e da ilegitimidade do Estado de criminalizar o uso da cannabis quando para fins medicinais.

No que diz respeito ao Pacto Internacional sobre Direitos Civis e Políticos, vê-se que a saúde aparece, várias vezes, como limitadora do legítimo uso das liberdades lá previstas. Além

6 ONU. Declaração Universal dos Direitos Humanos. 1948. Disponível em: https://www.unicef.org/brazil/pt/resources_10133.htm. Acesso em: 10/03/2019.

7 BOBBIO, Norberto. A era dos direitos; tradução de Carlos Nelson Coutinho. Rio de Janeiro: Elsevier, 2004. 
ISSN 1981-3694

(DOI): $10.5902 / 1981369437744$

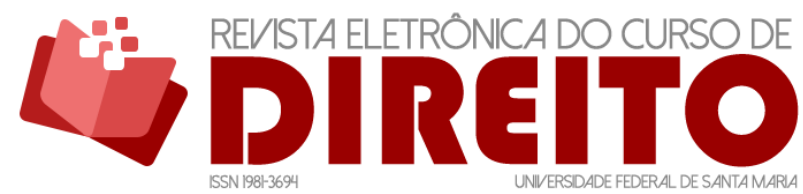

UMA ANÁLISE DA APLICAÇÃO DOS TRATADOS E CONVENÇÕES SOBRE DIREITOS HUMANOS NOS CASOS ENVOLVENDO O DIREITO

AO ACESSO À MACONHA MEDICINAL: UM ESTUDO A PARTIR DAS DEMANDAS JUDICIAIS ENVOLVENDO DERIVADOS DE CANNABIS NA

PARAÍBA

LUCIANO NASCIMENTO SILVA LUCAS LOPES OLIVEIRA

do mais, percebe-se que, como desdobramento do direito expresso no artigo 17, que veda ingerências arbitrárias na vida privada, estabelecendo o direito à proteção da vida privada, esse direito se desdobra na proteção da esfera de consciência e na liberdade de autodeterminação. Nesse sentido, seria ilegítimo o Estado criminalizar condutas que causam apenas dano ao próprio agente, pois o mesmo estaria apenas agindo conforme sua liberdade de ação. É justamente esse respeito à vida privada que é usado como argumento contra a criminalização da conduta de porte de drogas para uso pessoal, independente dos fins a que se destina o uso. Se é ilegítima a criminalização de condutas que causem somente mal ao indivíduo, mais ilegítima ainda é a criminalização de condutas que assegurem o bem-estar físico do indivíduo, como é o caso do uso medicinal da cannabis.

No que diz respeito ao Pacto Internacional sobre Direitos Econômicos, Sociais e Culturais, vê-se um adensamento da proteção do direito humano à saúde. Essa proteção está elencada no Artigo 12, que prevê que "os Estados Partes do presente Pacto reconhecem o direito de toda pessoa de desfrutar o mais elevado nível possível de saúde física e mental"8. Percebe-se uma expressão do direito à saúde densificado a partir dessa proteção expressa no referido tratado.

Quanto ao Sistema Interamericano de Proteção aos Direitos Humanos, o que se observa através da Convenção Americana sobre Direitos Humanos (Pacto de São José da Costa Rica) é justamente a necessidade de proteção ao direito à vida e à autonomia das pessoas, o que não se coaduna com ingerências no sentido de tentar evitar tratamentos médicos eficazes, estas que podem comprometer o direito à vida.

É nesse contexto que a ordem política internacional coloca o respeito aos direitos humanos como o patamar mais elevado de proteção do direito internacional. Conforme uma tendência das constituições contemporâneas, os direitos humanos, reconhecidos internacionalmente, acabaram sendo incorporados aos avanços constitucionais de várias nações. No Brasil, a Constituição de 1988 consagrou vários desses direitos humanos, chamando-os de direitos fundamentais, e as garantias jurídicas de proteção desses direitos foram chamadas de garantias fundamentais.

Entre tais direitos humanos constitucionalizados, está o direito à saúde previsto no artigo $6^{\circ}$ da CF de 1988, entre o rol dos direitos sociais. Também a saúde mereceu tratamento

\footnotetext{
${ }^{8}$ BRASIL. Decreto $n^{\circ}$ 591, de 6 de julho de 1992. Atos Internacionais. Pacto Internacional sobre Direitos Econômicos, Sociais e Culturais. Promulgação. Disponível em: http://www.planalto.gov.br/ccivil_03/decreto/1990-1994/d0591.htm. Acesso em: 18/09/2018.
} 
UMA ANÁLISE DA APLICAÇÃO DOS TRATADOS E CONVENÇÕES SOBRE DIREITOS HUMANOS NOS CASOS ENVOLVENDO O DIREITO

AO ACESSO À MACONHA MEDICINAL: UM ESTUDO A PARTIR DAS DEMANDAS JUDICIAIS ENVOLVENDO DERIVADOS DE CANNABIS NA

PARAÍBA

LUCIANO NASCIMENTO SILVA LUCAS LOPES OLIVEIRA

legal no artigo 196, que preceitua que "a saúde é direito de todos e dever do Estado, garantido mediante políticas sociais e econômicas que visem à redução do risco de doença e de outros agravos e ao acesso universal e igualitário às ações e serviços para sua promoção, proteção e recuperação"'. Essa característica do direito à saúde, de ser direito humano e dever do Estado, deve ser entendida de forma singular, de modo que

[...] o objeto dos deveres fundamentais decorrentes do direito à saúde guarda relação com as diferentes formas pelas quais esse direito fundamental é efetivado, podendo-se desde logo identificar - sem prejuízo de outras possíveis concretizações - uma dimensão defensiva, no dever de proteção da saúde, que se revela, por exemplo, pelas normas penais de proteção à vida, à integridade física, ao meio ambiente, à saúde pública, bem como em diversas normas administrativas no campo da vigilância sanitária, que regulam desde a produção e a comercialização de diversos tipos de insumos e produtos até o controle sanitário de fronteiras; e uma dimensão prestacional lato sensu, no dever de promoção à saúde, concretizada pelas normas e políticas públicas de regulamentação e organização do SUS, especialmente no que concerne ao acesso ao sistema, à participação da sociedade na tomada de decisões e no controle das ações de saúde e ao incentivo à adesão aos programas de saúde pública ${ }^{10}$.

Assim, em sua atuação como poder público, o Estado deve atuar tanto na implementação do direito à saúde, prestando assistência à saúde e fornecendo remédios diretamente, bem como através da fiscalização e prestação preventiva, do controle sanitário e do seu assim chamado poder de polícia administrativa. Ocorre que essa atuação deve ser efetivada de modo a garantir que o direito à saúde seja de fato efetivo, isto é, que a atuação do poder público produza significativo impacto na saúde da população. Caso uma dessas duas vertentes - atuação direta e atuação preventiva fiscalizadora - entre em conflito, deve-se sempre ter em mente os cidadãos concretos e não abstrações e categorias em descompasso com a realidade social. Desse modo, um excesso de fiscalização que obstaculize o exercício do direito à saúde, por via do acesso a um remédio, pode ser um exemplo de uma violação do Estado em seu dever de garantir o direito à saúde.

Como dito anteriormente, o direito à saúde constitui um direito social. Tal característica se relaciona à plataforma DESC - Direitos Econômicos, Sociais e Culturais, que demanda prestações positivas por parte do Estado. Tendo em vista esse caráter positivo que

9 BRASIL. Constituição da República Federativa do Brasil de 1988. Disponível em: http://www.planalto.gov.br/ccivil_03/Constituicao/Constituicao.htm. Acesso em: 10/03/2019.

10 SARLET, Ingo Wolfgang; FIGUEIREDO, Mariana Filchtiner. Algumas considerações sobre o direito fundamental à proteção e promoção da saúde aos 20 anos da Constituição Federal de 1988. Revista de Direito do Consumidor, v. 67, p. 125-172, 2008, p.6. 
UMA ANÁLISE DA APLICAÇÃO DOS TRATADOS E CONVENÇÕES SOBRE DIREITOS HUMANOS NOS CASOS ENVOLVENDO O DIREITO

AO ACESSO À MACONHA MEDICINAL: UM ESTUDO A PARTIR DAS DEMANDAS JUDICIAIS ENVOLVENDO DERIVADOS DE CANNABIS NA

PARAÍBA

LUCIANO NASCIMENTO SILVA LUCAS LOPES OLIVEIRA

demanda sua concretização, esses direitos são constantemente estudados, tendo em conta a constante crise de efetividade de sua realização. Maria Luiza Alencar ${ }^{11}$ aponta medidas importantes como forma de efetivar os direitos relacionados à plataforma DESC, entre os quais se encontra o direito à saúde. Primeiramente, por via legal, através da produção legislativa e da justiciabilidade de tais direitos para garantirem mecanismos processuais que permitam demandar tais direitos judicialmente, de modo que “[...] são justiciáveis grande parte dos direitos trabalhistas, também o direito à educação, o acesso às instituições educacionais públicas, à saúde, etc."12. Também seria possível, segundo a autora, a utilização de políticas públicas e monitoramento de metas de forma participativa e democrática.

Essa múltipla possibilidade de atuação na defesa do direito humano à saúde advém justamente de sua posição de destaque no ordenamento jurídico brasileiro. Esse desenho constitucional dado à saúde, na forma como foi posto pelo ordenamento jurídico brasileiro, pode ser concebido, segundo Cardoso e Feitosa ${ }^{13}$, como um direito juridicamente protegido, logo passível de ser demandado ao judiciário por via de entidades essenciais para a administração da justiça. Entende-se que seu âmbito de aplicação típica é o da efetivação de políticas públicas da saúde; sendo assim, cabendo ao Poder Executivo sua execução a partir do norte dado pelo Legislativo. Mas, aproveitando o pensamento de Cardoso e Feitosa ${ }^{14}$, torna-se clara a possibilidade de que, na ausência de efetividade desse direito, possa o mesmo ser demandado judicialmente. Nesse sentido,

[...] o direito à saúde adquiriu status não somente de direito coletivo, mas de direito múltiplo, ao mesmo tempo coletivo e difuso, com feições objetivas e subjetivas, merecendo ser tratado de modo especial, nomeadamente no que tange às formas de amparo judicial. São direitos processualmente garantidos ao ser humano e instrumentalizados pela ação de instituições republicanas, como o Ministério Público, a Defensoria Pública e demais atores legitimados pela Lei da

\footnotetext{
${ }^{11}$ MAYER, Maria Luiza Pereira de Alencar et al. Direitos humanos, econômicos, sociais e culturais. Prim@ Facie-Direito, História e Política, v. 5, n. 8, 2006.

12 MAYER, Maria Luiza Pereira de Alencar et al. Direitos humanos, econômicos, sociais e culturais. Prim@ Facie-Direito, História e Política, v. 5, n. 8, 2006. p. 44.

${ }^{13}$ CARDOSO, Henrique Ribeiro \& MAYER, Maria Luiza Pereira de Alencar. Direitos Sociais, Saúde Pública no Brasil, Precarização dos Vínculos Funcionais e Reflexos para o Usuário do Sistema Único de Saúde-SUS. Prim@ Facie-Direito, História e Política, v. 13, n. 25, p. 01-47, 2014. p. 04.

${ }^{14}$ CARDOSO, Henrique Ribeiro \& MAYER, Maria Luiza Pereira de Alencar. Direitos Sociais, Saúde Pública no Brasil, Precarização dos Vínculos Funcionais e Reflexos para o Usuário do Sistema Único de Saúde-SUS. Prim@ Facie-Direito, História e Política, v. 13, n. 25, p. 01-47, 2014.
} 
UMA ANÁLISE DA APLICAÇÃO DOS TRATADOS E CONVENÇÕES SOBRE DIREITOS HUMANOS NOS CASOS ENVOLVENDO O DIREITO

AO ACESSO À MACONHA MEDICINAL: UM ESTUDO A PARTIR DAS DEMANDAS JUDICIAIS ENVOLVENDO DERIVADOS DE CANNABIS NA

PARAÍBA

LUCIANO NASCIMENTO SILVA LUCAS LOPES OLIVEIRA

Ação Civil Pública, no sentido de demandarem do Judiciário providências para a tutela desse direito-dever, de natureza substancial e de execução específica ${ }^{15}$.

Então, cabe a quem se encontre em situação de vulnerabilidade frente à negativa de seu direito à saúde o direito de demandar judicialmente pela necessidade de obtenção de uma decisão que garanta a efetividade do direito à saúde. 0 caráter normativo desse direito acaba sendo muito criticado por autores em virtude do fenômeno social que envolve a judicialização da saúde. Os críticos desse fenômeno argumentam, entre outros pontos, que o privilegiamento de atuação do judiciário inter partes em casos individuais poderia impor uma reversão da lógica da soberania coletiva em detrimento dos interesses individuais, além de criticarem a efetivação de políticas públicas pelo judiciário quando do provimento de decisões judiciais em termos de saúde. Sarlet ${ }^{16} \mathrm{faz}$, em seu trabalho, um mapa importante desse debate, sempre considerando a tensão entre os interesses sociais e coletivos, destacando que, para além de ser uma pretensão judicial individual, quando demandada judicialmente, o direito à saúde tem uma dimensão coletiva. Além do mais, o referido autor destaca que, mesmo em sua dimensão individual, a realização de um indivíduo à saúde constitui uma forma de reforçar a esfera pública e o potencial da cidadania. Assim,

[...] o direito de cada indivíduo (individual ou coletivamente) buscar no âmbito do Poder Judiciário a correção de uma injustiça e a garantia de um direito fundamental, acaba, numa perspectiva mais ampla, por reforçar a esfera pública, pois o direito de ação assume a condição de direito de cidadania ativa e instrumento de participação do indivíduo no controle dos atos do poder público ${ }^{17}$.

Dessa forma, ante a questões complexas como a do direito à saúde e sua normatividade, a qual decorre sua possibilidade de ser demandada em juízo, é fundamental ter em conta a necessidade de analisar o direito à saúde de forma a levar em consideração seu caráter de direito humano e fundamental. Analisando o direito humano à saúde através dos dispositivos

\footnotetext{
${ }^{15}$ CARDOSO, Henrique Ribeiro \& MAYER, Maria Luiza Pereira de Alencar. Direitos Sociais, Saúde Pública no Brasil, Precarização dos Vínculos Funcionais e Reflexos para o Usuário do Sistema Único de Saúde-SUS. Prim@ Facie-Direito, História e Política, v. 13, n. 25, p. 01-47, 2014. p. 04.

${ }^{16}$ SARLET, Ingo Wolfgang. A titularidade simultaneamente individual e transindividual dos direitos sociais analisada à luz do exemplo do direito à proteção e promoção da saúde. Revista Brasileira De Direitos Fundamentais \& Justiça, 4(10), 205-228, 2010. https://doi.org/10.30899/dfj.v4i10.449.

17 SARLET, Ingo Wolfgang. A titularidade simultaneamente individual e transindividual dos direitos sociais analisada à luz do exemplo do direito à proteção e promoção da saúde. Revista Brasileira De Direitos Fundamentais \& Justiça, 4(10), 205-228, 2010. https://doi.org/10.30899/dfj.v4i10.449. p. 226.
} 
ISSN 1981-3694

(DOI): $10.5902 / 1981369437744$

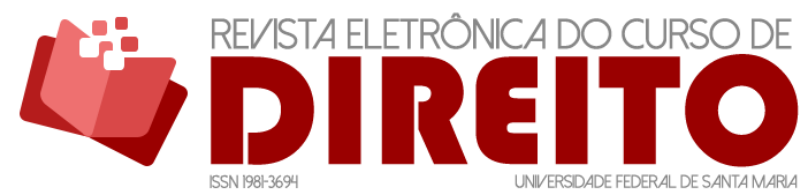

UMA ANÁLISE DA APLICAÇÃO DOS TRATADOS E CONVENÇÕES SOBRE DIREITOS HUMANOS NOS CASOS ENVOLVENDO O DIREITO

AO ACESSO À MACONHA MEDICINAL: UM ESTUDO A PARTIR DAS DEMANDAS JUDICIAIS ENVOLVENDO DERIVADOS DE CANNABIS NA

PARAÍBA

LUCIANO NASCIMENTO SILVA LUCAS LOPES OLIVEIRA

normativos expressos nos dois principais tratados internacionais de direitos humanos da ONU e sua recepção no texto constitucional brasileiro e no pensamento jurídico acadêmico, observa-se a importância dos estudos sobre o direito à saúde na práxis jurídica dos órgãos do poder judiciário.

\section{A PROBLEMÁTICA DO USO DA MACONHA MEDICINAL: UMA ANÁLISE A PARTIR DOS TRATADOS SOBRE DIREITOS HUMANOS}

A questão do direito ao acesso à maconha medicinal, no Brasil, tem sido bastante discutida nas mídias, na academia, nos espaços públicos, nos parlamentos e nos tribunais. Esse debate se popularizou a partir da militância de familiares que lutaram pelo direito à saúde e à vida de seus entes queridos. Casos de crianças com epilepsia refratária aos tratamentos convencionais sensibilizaram muitas pessoas, como no caso da menina Anny Fischer que teve sua história contada no documentário “Ilegal: a vida não espera” de Tarso Araújo ${ }^{18}$. A partir da articulação política, da militância e de trabalhos nas mídias sociais e tradicionais, essa causa pôde sensibilizar a opinião pública para a necessidade de reforma da política de drogas no que diz respeito à cannabis sativa e seu uso medicinal.

Essa luta se liga às novas concepções sobre o exercício da cidadania e a luta por direitos humanos na contemporaneidade e desafia o judiciário a se reinventar na sua função com relação à aplicação da lei. A maior compreensão sobre as interações moleculares permitiu cada vez mais descobrir os potenciais terapêuticos da cannabis e a possibilidade dessa planta e seus compostos serem usados no tratamento de várias doenças. Esta maior conscientização fez com que pacientes e familiares buscassem gradualmente a utilização de remédios à base de cannabis, recorrendo, muitas vezes, à ilegalidade. Nesse processo, houve importantes estratégias de judicialização que visavam superar a barreira da ilegalidade imposta pelo Estado, e importantes vitórias judiciais que permitiram a classificação do canabidiol e do THC como substâncias controladas, o fornecimento gratuito de medicamentos via Sistema Único de Saúde e até a possibilidade de plantio coletivo e individual de cannabis para fins medicinais.

Mesmo havendo dispositivos jurídicos que poderiam ser interpretados de forma a restringir e criminalizar a busca de uma melhor qualidade de vida a partir do uso da maconha, a

18 ARAÚJO, Tarso. ILEGAL: A vida não espera. Documentário. $90 \mathrm{~min}$, 2014. Disponível em: https: / /www.youtube.com/watch?v=I-072T0enO4. Acessado em: 04/06/2015. 
ISSN 1981-3694

(DOI): $10.5902 / 1981369437744$

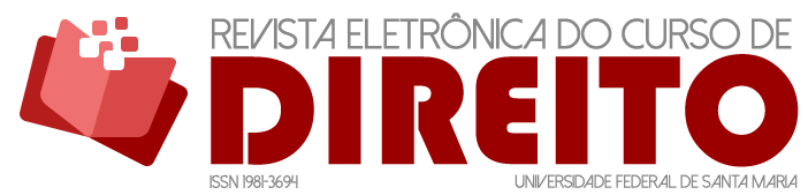

UMA ANÁLISE DA APLICAÇÃO DOS TRATADOS E CONVENÇÕES SOBRE DIREITOS HUMANOS NOS CASOS ENVOLVENDO O DIREITO

AO ACESSO À MACONHA MEDICINAL: UM ESTUDO A PARTIR DAS DEMANDAS JUDICIAIS ENVOLVENDO DERIVADOS DE CANNABIS NA

PARAÍBA

LUCIANO NASCIMENTO SILVA LUCAS LOPES OLIVEIRA

presença de normativas internacionais vigentes, no Brasil, bem como as disposições constitucionais são suficientes para afastar qualquer interpretação em sentido que restrinja o direito à saúde de pacientes que usam maconha medicinal. Essa prevalência implica o uso dos dispositivos do poder jurídico de forma a instrumentalizá-la contra interpretações e aplicações do direito que violem direitos humanos. Nesse ponto, concorda-se com Foucault ${ }^{19}$, para quem todo o poder pressupõe que haja também resistência e, por conseguinte, toda a resistência se dá a partir do próprio poder em uma relação interna. A utilização de categorias jurídicas de forma a garantir os direitos humanos, inclusive contra o Estado, constitui um exemplo de luta e de mobilização do poder jurídico, tornando-o uma importante ferramenta. Essa leitura implica observar o poder como teias de relações que não se limitam ao Estado, mas incluem o Estado, tecem importantes influências nas estruturas políticas e nas formas de subjetividade, sejam dóceis ou dissidentes.

A efetivação dos direitos vista sob a ótica não apenas da realização do Estado, mas sim da participação ativa dos envolvidos, é algo que caracteriza a luta pela cidadania ativa contemporânea e que tem expressão na luta de pacientes e seus familiares no acesso a remédios à base de cannabis. As mudanças que os fluxos comunicacionais e informacionais imprimiram às formas de sociabilidade contemporânea são algo bastante estudado por Nikolas Rose ${ }^{20}$. Ao analisar o impacto que a maior compreensão molecular e da saúde humana reflete sobre o direito à saúde, o autor utiliza a expressão biocidadania, que seria uma das dimensões da política sobre a vida contemporânea que impacta sobre as formas de subjetivação.

Conhecendo mais sobre as possibilidades de escolhas e os novos conhecimentos sobre a maconha, é possível o exercício de maior autonomia nos processos de cura que impacta no ativismo em busca da concretização do direito à saúde negado pelas pretensões normalizadoras e moralizadoras do Estado.

Atualmente, no Brasil, a atual Lei de Drogas tipifica criminalmente várias condutas de pessoas que portam ou plantam substâncias proscritas. A lista das substâncias está expressa na Portaria SVS/MS n 344 da Agência Nacional de Vigilância Sanitária - ANVISA que regula tal questão. Está-se diante, portanto, do que a doutrina penal chama de norma penal em branco, que funciona quando o Poder Legislativo delega ao Executivo a possibilidade de delimitar o âmbito de criminalização já preliminarmente apresentado pela lei penal criminalizadora. Dessa

\footnotetext{
${ }^{19}$ FOUCAULT, Michel. História da sexualidade I: A vontade de saber. São Paulo: Paz e Terra, 2014.

${ }^{20}$ ROSE, Nikolas. A política da própria vida: biomedicina, poder e subjetividade no século XXI. São Paulo: Paulus, 2013.
} 
UMA ANÁLISE DA APLICAÇÃO DOS TRATADOS E CONVENÇÕES SOBRE DIREITOS HUMANOS NOS CASOS ENVOLVENDO O DIREITO

AO ACESSO À MACONHA MEDICINAL: UM ESTUDO A PARTIR DAS DEMANDAS JUDICIAIS ENVOLVENDO DERIVADOS DE CANNABIS NA

PARAÍBA

LUCIANO NASCIMENTO SILVA LUCAS LOPES OLIVEIRA

forma, é possível ao Poder Executivo ampliar a área de incidência da lei penal. Tal sistemática tem sido bastante criticada por parte da doutrina, principalmente por gerar insegurança jurídica e ferir o princípio da legalidade penal, um dos maiores nortes do Direito Penal iluminista ${ }^{21}$.

É importante observar que uma pessoa que porte ou use maconha para o tratamento próprio ou de familiar pode vir a responder pelos delitos de porte para consumo, tráfico de drogas ou outros delitos tipificados pela norma penal, devido a interpretações jurídicas descontextualizadas por parte dos órgãos responsáveis pela persecução penal. Nesse sentido, torna-se fundamental uma revisão nesta perspectiva de modo a garantir que pessoas não sejam presas quando da busca por seu tratamento.

Além desse dispositivo legal sobre o tema no direito brasileiro, tem-se também os instrumentos internacionais da ONU que regulam a questão das drogas. Assim, no Brasil, foram internalizadas as três Convenções das Nações Unidas sobre Drogas, quais sejam a Convenção Única Sobre Estupefacientes de 1961, emendada através do Protocolo de 1962; a Convenção sobre Substâncias Psicotrópicas de 1971; e a Convenção Contra Tráfico Ilícito de Drogas Narcóticas e Substâncias Psicotrópicas de 1988. Especificamente em relação à maconha, os principais dispositivos que a regulam no âmbito internacional e que foram recepcionados pelo ordenamento jurídico brasileiro estão contidos na Convenção Única Sobre Estupefacientes. Essa Convenção é considerada um marco internacional na estruturação do proibicionismo mundial das drogas, dando fundamento normativo internacional a partir da imposição de condutas às nações que, caso não cumpridas ou não acordadas, gerariam sanções políticas e econômicas ${ }^{22}$. Segundo Lippi $^{23}$, a Convenção Única foi uma importante ferramenta de controle geopolítico sobre a América Latina e a Ásia, por focar a repressão amplamente produzida por esses continentes como a coca, a cannabis e a dormideira. A referida convenção criou um interdito mundial para a maconha e outras plantas e substâncias classificadas como drogas nocivas.

Ela instituiu um amplo sistema internacional de controle e atribuiu a responsabilidade aos estados-parte de incorporação das medidas ali previstas em suas legislações nacionais, além de ter reforçado o controle sobre a produção, distribuição e comércio de drogas nos países nacionais, e proibido expressamente

${ }^{21}$ CARVALHO, Salo de. A política criminal de drogas no Brasil: estudo criminológico e dogmático. 6 ed. São Paulo: Saraiva 2013.

22 BOITEUX, Luciana. Controle penal sobre as drogas ilícitas: o impacto do proibicionismo no sistema penal e na sociedade. Programa de Pós-Graduação em Direito, Faculdade de Direito, Universidade de São Paulo. Tese de Doutorado. São Paulo, 2006, $237 \mathrm{f}$.

${ }^{23}$ LIPPI, Camila Soares. O discurso das drogas construído pelo direito internacional. Revista de Direito Internacional, v. 10, n. 2, p.53-65, 2014. 
UMA ANÁLISE DA APLICAÇÃO DOS TRATADOS E CONVENÇÕES SOBRE DIREITOS HUMANOS NOS CASOS ENVOLVENDO O DIREITO

AO ACESSO À MACONHA MEDICINAL: UM ESTUDO A PARTIR DAS DEMANDAS JUDICIAIS ENVOLVENDO DERIVADOS DE CANNABIS NA

PARAÍBA

LUCIANO NASCIMENTO SILVA LUCAS LOPES OLIVEIRA

o fumo e a ingestão de ópio, assim como o simples mastigamento da folha de coca e o uso não médico da cannabis ${ }^{24}$.

Ocorre que, apesar da proibição da cannabis pela Convenção de 1961, não houve a proibição do uso medicinal da referida planta. Assim, como destacam Mattos ${ }^{25}$ e Oliveira e Ribeiro $^{26}$, a Convenção Única, longe de proibir o uso medicinal, resguarda-o juridicamente. Esta pretensão de resguardar o uso médico da cannabis e de outras plantas proscritas se encontra no preâmbulo do referido documento, “[...] reconhecendo que o uso médico dos entorpecentes continua indispensável para o alívio da dor e do sofrimento e que medidas adequadas devem ser tomadas para garantir a disponibilidade de entorpecentes para tais fins"27, bem como está legitimado pelos artigos 21 e 28. No artigo 21, ao trazer a limitação das drogas e de sua produção, preceitua que "a quantidade total de cada entorpecente fabricado ou importado por cada país ou território, em um ano, não excederá as somas seguintes: a) a quantidade consumida, dentro dos limites da estimativa correspondente para fins médicos ou científicos; [...]"28. Essa convenção foi recepcionada pelo direito brasileiro, sendo, portanto, aplicável e tendo força de lei. Não há, assim, nenhuma forma de alegar que a descriminalização do uso da cannabis para fins medicinais ou sua plena regulamentação poderia ocasionar alguma violação ao sistema de controle de drogas da ONU. Esse é um argumento frequentemente levantado pelos que se posicionam contra a regulamentação da maconha medicinal e que advém de uma leitura precipitada dessas Convenções.

Também, e não menos importante, é bom lembrar que, em caso de conflito entre o direito internacional que regula o sistema de controle de drogas da ONU e algum tratado internacional de proteção aos direitos humanos, resta por oportuno afirmar que o segundo

${ }^{24}$ BOITEUX, Luciana. Controle penal sobre as drogas ilícitas: o impacto do proibicionismo no sistema penal e na sociedade. Programa de Pós-Graduação em Direito, Faculdade de Direito, Universidade de São Paulo. Tese de Doutorado. São Paulo, 2006, 237 f, p. 39.

${ }^{25}$ MATTOS, Paulo E. Orlandi. Modelos internacionais de regulamentação do uso medicinal da cannabis. In: Drogas no Brasil: entre a saúde e a justiça: proximidades e opiniões / Vilma Bokany (org.). São Paulo: Editora Fundação Perseu Abramo, 2015.

${ }^{26}$ OLIVEIRA, Lucas Lopes; RIBEIRO, Luziana Ramalho. DISCURSOS MÉDICOS E JURÍDICOS SOBRE MACONHA NA PARAÍBA: a judicialização do direito ao acesso à maconha medicinal. Revista de Estudos Empíricos em Direito, v. 4, n. 2, 2017.

27 BRASIL. Decreto 54.216, de 27 de agosto de 1964. Convenção Única Sobre Estupefacientes. Disponível em: http://www2.camara.leg.br/legin/fed/decret/1960-1969/decreto-54216-27-agosto-1964-394342publicacaooriginal-1-pe.html. Acesso em: 12 set. 2018.

28 BRASIL. Decreto 54.216, de 27 de agosto de 1964. Convenção Única Sobre Estupefacientes. Disponível em: http://www2.camara.leg.br/legin/fed/decret/1960-1969/decreto-54216-27-agosto-1964-394342publicacaooriginal-1-pe.html. Acesso em: 12 set. 2018. 
UMA ANÁLISE DA APLICAÇÃO DOS TRATADOS E CONVENÇÕES SOBRE DIREITOS HUMANOS NOS CASOS ENVOLVENDO O DIREITO

AO ACESSO À MACONHA MEDICINAL: UM ESTUDO A PARTIR DAS DEMANDAS JUDICIAIS ENVOLVENDO DERIVADOS DE CANNABIS NA

PARAÍBA

LUCIANO NASCIMENTO SILVA LUCAS LOPES OLIVEIRA

sempre deverá prevalecer sobre o primeiro, em virtude da preferência que os direitos humanos têm na ordem internacional sobre qualquer outro tema regulamentado pelo direito internacional ${ }^{29}$.

Nesse sentido, destaca Boiteux ${ }^{30}$ o quão complexa é a relação entre o sistema normativo internacional de controle sobre drogas e o sistema internacional de proteção de direitos humanos. Esses sistemas que, em tese, deveriam funcionar de forma harmônica, daí a ideia de sistema jurídico internacional que expressaria o direito internacional, na verdade expressam uma contradição de difícil solução.

Levando em conta esta importante concepção, podemos dizer que, enquanto os tratados internacionais de controle de drogas representam uma velha ordem com base na razão de estado, o direito internacional de direitos humanos está diretamente ligado a razões humanitárias, comuns a todos os homens, sem distinção de origem, gênero, orientação sexual, nacionalidade, religião, etnia, cor, língua, opinião política ou de quaisquer outros critérios ${ }^{31}$.

Nesse sentido, percebe-se a necessidade de prevalência dos direitos humanos sobre qualquer dispositivo que impeça, ainda que indiretamente, o exercício ou o gozo de algum direito proclamado e positivado em âmbito internacional. Também foi visto que restou afastada qualquer interpretação que uma possível regulação da maconha para fins medicinais por parte de algum país membro da ONU poderia acarretar sanções. Com tudo isto em vista, torna-se extremamente necessário que o Estado brasileiro tome medidas de forma a garantir o direito ao acesso à maconha medicinal por parte dos pacientes que dependem dessa planta. Essa situação requer atitudes positivas por parte do Estado para a efetiva adequação das suas normas internas aos ditames da fiel proteção dos direitos humanos. Assim, os tratados internacionais de direitos humanos, segundo a doutrina jurídica, podem impor obrigações aos órgãos do direito interno de modo a assegurarem os direitos por eles expressos.

${ }^{29}$ BOITEUX, Luciana et al. DIREITOS HUMANOS E CONVENÇÕES INTERNACIONAIS DE DROGAS: Em Busca de uma Razão Humanitária nas Leis de Drogas. In: Drogas e direitos humanos: reflexões em tempos de guerra às drogas [recurso eletrônico] / Marcelo Dalla Vecchia ... [et al.] organizadores. - 1.ed. - Porto Alegre : Rede UNIDA, 2017.

${ }^{30}$ BOITEUX, Luciana et al. DIREITOS HUMANOS E CONVENÇÕES INTERNACIONAIS DE DROGAS: Em Busca de uma Razão Humanitária nas Leis de Drogas. In: Drogas e direitos humanos: reflexões em tempos de guerra às drogas [recurso eletrônico] / Marcelo Dalla Vecchia ... [et al.] organizadores. - 1.ed. - Porto Alegre : Rede UNIDA, 2017.

31 BOITEUX, Luciana et al. DIREITOS HUMANOS E CONVENÇÕES INTERNACIONAIS DE DROGAS: Em Busca de uma Razão Humanitária nas Leis de Drogas. In: Drogas e direitos humanos: reflexões em tempos de guerra às drogas [recurso eletrônico] / Marcelo Dalla Vecchia ... [et al.] organizadores. - 1.ed. - Porto Alegre : Rede UNIDA, 2017. p. 240. 
UMA ANÁLISE DA APLICAÇÃO DOS TRATADOS E CONVENÇÕES SOBRE DIREITOS HUMANOS NOS CASOS ENVOLVENDO O DIREITO

AO ACESSO À MACONHA MEDICINAL: UM ESTUDO A PARTIR DAS DEMANDAS JUDICIAIS ENVOLVENDO DERIVADOS DE CANNABIS NA

PARAÍBA

\begin{abstract}
Os tratados de direitos humanos indicam vias de compatibilização dos dispositivos convencionais com os mecanismos do direito interno, de modo a prevenir conflitos entre as jurisdições internacional e nacional. Eles impõem aos Estados Partes o dever de provimento de recursos de direito interno eficazes e, por vezes, a possibilidade de "recurso judicial". Além de preverem a adoção pelos Estados Partes de medidas legislativas, judiciais, administrativas ou outras para a realização de seu objeto e propósito. Enfim, contam com o concurso dos órgãos e procedimentos de direito público interno, promovendo uma interpenetração nos dois âmbitos de direito. Os órgãos internos dos Estados são chamados a aplicar as normas internacionais. Este é o traço distintivo dos tratados de direitos humanos, dotados de especificidade própria, e que requerem uma interpretação adequada, guiada pelos valores comuns superiores que abrigam, diferentemente dos tratados clássicos que se limitavam a regular a atuação entre as partes ${ }^{32}$.
\end{abstract}

Desse modo, identificada uma ausência de regulamentação ou uma proibição expressa por parte do direito de um Estado, os tratados de direitos humanos constituem normas capazes de impor obrigações ao Estado e seus poderes de modo a garantir o efetivo gozo dos direitos humanos. Tendo em vista que houve a incorporação de vários tratados de direitos humanos que garantem o direito à saúde e que tais tratados, ao adentrarem o ordenamento jurídico nacional, ganham um status de supralegalidade, ou seja, estão hierarquicamente abaixo da constituição, mas acima da legislação ordinária nacional, deve ser afastada a aplicação de qualquer norma ordinária que entre em conflito com os direitos expressos nesses tratados.

$\mathrm{Na}$ verdade, esse tem sido um consenso entre constitucionalistas e internacionalistas: o status jurídico de supralegalidade concedido aos tratados de direitos humanos. Além do mais, no plano internacional, resta por oportuno a implementação de um importante critério hermenêutico de soluções de antinomias em relação ao Direito Internacional dos Direitos Humanos e o Direito Interno, qual seja o da prevalência da norma mais protetiva à pessoa humana:

[...] na hipótese de eventual conflito entre o Direito Internacional dos Direitos Humanos e o Direito interno, adota-se o critério da prevalência da norma mais favorável à vítima. Em outras palavras, a primazia é da norma que melhor proteja, em cada caso, os direitos da pessoa humana ${ }^{33}$.

32 BOITEUX, Luciana; PIRES, Thula Rafaela de Oliveira; BATISTA, Vanessa Oliveira. Direitos Humanos. Convocação 01/2007. Série pensando o direito No 5/2009 - versão publicação. Ministério da Justiça, 2009, p.20.

33 PIOVESAN, Flávia. Direitos humanos e o direito constitucional internacional. São Paulo: Saraiva, 2013. 
UMA ANÁLISE DA APLICAÇÃO DOS TRATADOS E CONVENÇÕES SOBRE DIREITOS HUMANOS NOS CASOS ENVOLVENDO O DIREITO

AO ACESSO À MACONHA MEDICINAL: UM ESTUDO A PARTIR DAS DEMANDAS JUDICIAIS ENVOLVENDO DERIVADOS DE CANNABIS NA

PARAÍBA

LUCIANO NASCIMENTO SILVA LUCAS LOPES OLIVEIRA

Também é oportuno lembrar que, em virtude de a saúde estar entre os direitos reconhecidos pela $\mathrm{CF}$, um conflito aparente de normas em relação ao direito à saúde constitucionalmente garantido e qualquer norma só pode ser resolvido através do reconhecimento da inconstitucionalidade da norma infraconstitucional. Essa prevalência no conflito de normas pode se dar tanto no caso concreto quanto em abstrato.

\section{ANÁLISE DA ATUAÇÃO DO MPF-PB NA DEFESA DOS DIREITOS DOS PACIENTES DE MACONHA MEDICINAL E OS MARCOS LEGAIS INTERNACIONAIS DE DIREITOS HUMANOS}

A partir desses marcos legais é que está sendo possível a construção de alternativas aos pacientes que necessitam da maconha medicinal para a proteção de seu direito à saúde por via de remédios derivados da cannabis. Como destacou Oliveira ${ }^{34}$, esse processo de luta pela maconha medicinal se deu através da mobilização de categorias do discurso médico de forma a produzir, dentro da estrutura do judiciário, uma releitura do potencial terapêutico da maconha, que passaria a ser vista como remédio por parte dos juízes, afastando o preconceito antes existente. Foram essas mudanças de percepção da cultura jurídica que produziram importantes modificações que permitiram a emergência de várias sentenças favoráveis à causa.

As categorias do discurso médico servem como forma de ligar o uso de remédios derivados da maconha ao direito à saúde. São várias as provas técnicas expressas em artigos científicos, pareceres e comunicações que relatam a potencialidade dos canabinoides para o tratamento das doenças narradas nas petições. Em “Os Anormais”, Michel Foucault ${ }^{35}$ narra como a tradicional forma de administração da justiça baseada no lluminismo vai cedendo espaço para o imbricamento, dentro da lógica jurídica, do discurso médico. Daí a importância deste discurso na constituição das provas e na formação do convencimento dos órgãos julgadores. Ocorre que, se nos tempos do higienismo este agregado prezava pela moralização das práticas judiciárias através da categorização moral de doenças em razão da própria estrutura cientificista da época,

34 OLIVEIRA, Lucas Lopes. Discursos médicos e jurídicos sobre maconha no Brasil e na Paraíba: os contradiscursos no debate sobre as políticas de drogas à luz dos direitos humanos. (Dissertação de Mestrado). Programa de Pós-Graduação em Direitos Humanos, Cidadania e Políticas Públicas PPGDH/UFPB, 2016.

${ }^{35}$ FOUCAULT, Michel. Os Anormais: Curso no College de France (1974-1975). São Paulo: Martins Fontes, 2002. 
ISSN 1981-3694

(DOI): $10.5902 / 1981369437744$

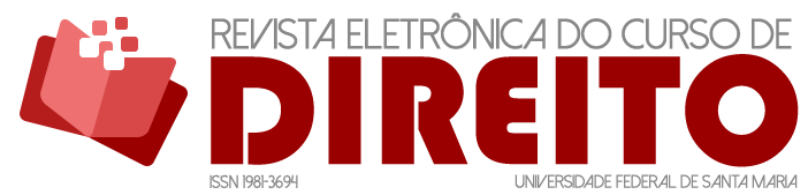

UMA ANÁLISE DA APLICAÇÃO DOS TRATADOS E CONVENÇÕES SOBRE DIREITOS HUMANOS NOS CASOS ENVOLVENDO O DIREITO

AO ACESSO À MACONHA MEDICINAL: UM ESTUDO A PARTIR DAS DEMANDAS JUDICIAIS ENVOLVENDO DERIVADOS DE CANNABIS NA

PARAÍBA

LUCIANO NASCIMENTO SILVA LUCAS LOPES OLIVEIRA

nos tempos atuais a influência do poder médico pode trazer releituras principalmente por aproveitar todo um conjunto de transformações na epistemologia médica e os impactos do discurso dos direitos humanos e de defesa da autonomia e do empoderamento de pacientes provocados pela democratização da política de saúde. Nesse sentido, opina Nikolas Rose ${ }^{36}$ sobre as possibilidades do impacto do discurso médico como forma de reforço da cidadania ativa de pacientes através de uma política da vida baseada em uma biocidadania informacional.

É a partir destas considerações que se passa a observar como o discurso jurídico dos direitos humanos impacta na atividade judicial de defesa dos direitos dos pacientes de maconha medicinal, tendo sempre em conta a influência recíproca entre saber, poder e discurso ${ }^{37}$.

$\mathrm{Na}$ Paraíba, uma dessas ações pioneiras na efetivação do direito ao acesso à maconha medicinal foi responsável pela autorização de importação de derivados da cannabis ricos em CBD. Intentada pelo Ministério Público Federal através da Procuradoria Regional dos Direitos do Cidadão sob a forma de uma Ação Civil Pública - ACP, processo número 080254314.2014.4.05.8200, várias famílias conseguiram garantir o direito de importar seus remédios. No contexto em que se deu a ação judicial, não havia a possibilidade legal de utilização de canabinoides, pois nenhum deles estava classificado como substância passível de uso, ainda que de forma controlada pela ANVISA. A possibilidade de importação dos canabinoides CBD e THC só ocorreria com a publicação de portarias por parte da ANVISA em momento posterior. A ação se instaurou a partir da provocação de um grupo de pais e mães da Paraíba que protocolaram junto ao MPF-PB requerimento que deu origem ao Procedimento Preparatório - PP 1.24.000.001421/2014-74. Através desse inquérito, foram construídos os argumentos legais e técnicos para subsidiar a ação que garantiu o direito de importar medicamentos à base de CBD para essas famílias.

Além da Ação Civil Pública que visava garantir o direito à importação pelos pacientes do Estado da Paraíba, esse PP acabou gerando outras duas importantes atuações judiciais: uma Ação Civil Pública que visava garantir o fornecimento gratuito de medicamentos pelo Sistema Único de Saúde e um posicionamento, a partir de um parecer positivo, no processo movido pela Associação Brasileira de Apoio Cannabis Esperança - ABRACE com o intuito de garantir o direito de plantar e produzir medicamentos para seus associados. Além dessas atuações judiciais, o

\footnotetext{
${ }^{36}$ ROSE, Nikolas. A política da própria vida: biomedicina, poder e subjetividade no século XXI. São Paulo: Paulus, 2013.

${ }^{37}$ FOUCAULT, Michel. A Verdade e as Formas Jurídicas. 3. ed. Rio de Janeiro: Nau, 2009.
} 
UMA ANÁLISE DA APLICAÇÃO DOS TRATADOS E CONVENÇÕES SOBRE DIREITOS HUMANOS NOS CASOS ENVOLVENDO O DIREITO

AO ACESSO À MACONHA MEDICINAL: UM ESTUDO A PARTIR DAS DEMANDAS JUDICIAIS ENVOLVENDO DERIVADOS DE CANNABIS NA PARAÍBA

órgão também teve importante atuação extrajudicial de forma a garantir procedimentos necessários ao exercício dos direitos dos pacientes, mostrando-se parceiro do movimento social.

Muitos dos argumentos enunciados pela petição inicial, que garantiu o direito à importação, reproduziam justamente os preceitos legais dos Tratados e Convenções sobre Direitos Humanos dos quais o Brasil faz parte. Essa formação discursiva foi realizada com a ajuda do Projeto de Extensão Universitário "Acesso à Jurisdição Internacional do Sistema Interamericano de Direitos Humanos" da Universidade Federal da Paraíba, que elaborou parecer sobre o tema. Ao analisar, de forma ampla e densa, a legislação internacional sobre a proteção dos direitos humanos no âmbito internacional, o parecer emitido pelo referido projeto de extensão universitária se destaca ao opinar que,

por tudo exposto, conclui-se configurada a omissão inconvencional do Estado, uma vez que a não prestação dos remédios adequados aos enfermos e a falta de um tratamento qualificado estão em desacordos com os standards estabelecidos pelas Convenções da ONU sobre entorpecentes; Convenção dos Direitos da Pessoa com Deficiência e com a Convenção Americana sobre Direitos Humanos, e sua jurisprudência correlata ${ }^{38}$.

Trechos desse parecer são reproduzidos na petição inicial do MPF, demonstrando a grande influência do trabalho da Extensão Universitária da UFPB no processo de defesa dos direitos das famílias à saúde, mas também representa a importância da linha argumentativa a partir dos direitos humanos e do sistema internacional de proteção aos direitos humanos ${ }^{39}$.

Quando da tentativa de fornecimento gratuito de remédios pelo SUS, peticionada no Processo $n^{\circ}$ 0802271-83.2015.4.05.8200, também houve a invocação do direito internacional com fito de garantir pretensão que resguardasse o direito das pessoas que dependiam de remédios derivados da cannabis, mas, por causa dos grandes custos de aquisição, tinham sua saúde comprometida e sua vida ameaçada. Destaca-se a importância da legislação internacional nos

\footnotetext{
38 BRASIL. Ministério Público Federal. Procedimento Preparatório n 1.24.000.001421/2014-74. PFDC. Saúde. Canabidiol. Acesso à medicação. Reclassificação junto à ANVISA. Disponibilidade pelo SUS. Partes: representante: Sheila e outros; representados: ANVISA, 2014. Autuado 09/07/2014, p. 290.

39 BRASIL. Justiça Federal. Ação Civil Pública nº 0802543-14.2014.4.05.8200, ajuizada em 31 de julho de $2014\left(1^{\text {a }}\right.$ Vara Federal). In: BRASIL. Ministério Público Federal. Procedimento Preparatório $\mathrm{n}^{\circ}$ 1.24.000.001421/2014-74. PFDC. Saúde. Canabidiol. Acesso à medicação. Reclassificação junto à ANVISA. Disponibilidade pelo SUS. Partes: representante: Sheila e outros; representados: ANVISA, 2014. Autuado 09/07/2014.
} 
UMA ANÁLISE DA APLICAÇÃO DOS TRATADOS E CONVENÇÕES SOBRE DIREITOS HUMANOS NOS CASOS ENVOLVENDO O DIREITO

AO ACESSO À MACONHA MEDICINAL: UM ESTUDO A PARTIR DAS DEMANDAS JUDICIAIS ENVOLVENDO DERIVADOS DE CANNABIS NA

PARAÍBA

LUCIANO NASCIMENTO SILVA LUCAS LOPES OLIVEIRA

trabalhos realizados judicialmente pelo Ministério Público Federal da Paraíba no âmbito desse processo $^{40}$.

Essa importância se dá de forma tão intensa que, em momento posterior, ao ser chamado a opinar como fiscal da lei na ação que envolvia o pedido da autorização para o cultivo e manipulação de cannabis sativa realizado pela ABRACE no processo 080033382.2017.4.05.8200, o MPF-PB, por via da Manifestação $n^{\circ}$. 3201/2017/MPF/PRPB/GAB-JGBS, reitera a necessidade de proteção ao direito à saúde de pacientes e se manifesta pelo direito da associação de produzir remédios à base de cannabis. Destaca-se neste parecer um tópico específico sobre a Proteção no Âmbito do Direito Internacional, em que o parquet novamente reitera os argumentos baseados na legislação internacional de proteção aos direitos humanos. Ao fazê-lo, ele volta a citar o parecer emitido pelo Projeto de Extensão “Acesso à Jurisdição Internacional do Sistema Interamericano de Direitos Humanos" e a defesa dos direitos das pessoas que usam derivados da cannabis como medicamentos. Desse modo, com fundamento no Direito Internacional dos Direitos Humanos, o MPF argumenta:

Hoje, o Direito Internacional conclama pela Interpretação pro homine, premissa hermenêutica pela qual a aplicação das Convenções internacionais deve se dar de forma mais benéfica aos Direitos Humanos. Então, ainda que faltasse a regulamentação doméstica, tal argumentação não pode eximir o Estado de observar esses Tratados, sendo configurada uma omissão inconvencional a negligência cumprir os preceitos do Sistema Internacional de Direitos Humanos ${ }^{41}$.

Assim, nesses dois importantes momentos, na ação intentada pelo MPF para a autorização de importação de remédios à base de CBD, bem como no parecer emitido em favor do pedido da ABRACE, uma importante ferramenta de convencimento foi as normativas internacionais sobre direitos humanos, tendo destaque a produção de conhecimento expressa no parecer produzido pela Instituição Federal de Ensino.

A primeira ACP foi extremamente importante por ter sido a primeira ação coletiva a conseguir a importação de remédios à base de CBD no Brasil, sendo um marco na história da luta pela maconha medicinal. A segunda ACP teve liminar favorável, garantindo o fornecimento

${ }^{40}$ BRASIL. Justiça Federal. Ação Civil Pública nº 0802271-83.2015.4.05.8200, ajuizada em 15 de junho de 2015 ( $3^{\text {a }}$ Vara Federal), 2015.

41 BRASIL. Manifestação $n^{\circ}$. 3201/2017/MPF/PRPB/GAB-JGBS. Justiça Federal. Processo 080033382.2017.4.05.8200. Autora: ABRACE. In: BRASIL. Ministério Público Federal. Procedimento Preparatório n 1.24.000.001421/2014-74. PFDC. Saúde. Canabidiol. Acesso à medicação. Reclassificação junto à ANVISA. Disponibilidade pelo SUS. Partes: representante: Sheila e outros; representados: ANVISA, 2014. Autuado 09/07/2014. p. 816. 
ISSN 1981-3694

(DOI): $10.5902 / 1981369437744$

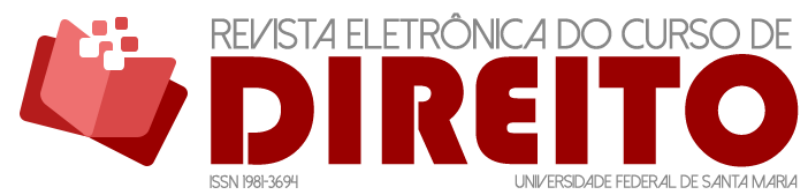

UMA ANÁLISE DA APLICAÇÃO DOS TRATADOS E CONVENÇÕES SOBRE DIREITOS HUMANOS NOS CASOS ENVOLVENDO O DIREITO

AO ACESSO À MACONHA MEDICINAL: UM ESTUDO A PARTIR DAS DEMANDAS JUDICIAIS ENVOLVENDO DERIVADOS DE CANNABIS NA

PARAÍBA

LUCIANO NASCIMENTO SILVA LUCAS LOPES OLIVEIRA

gratuito por parte do SUS, mas essa liminar foi revogada em segunda instância sob o argumento da reserva do possível. A terceira manifestação judicial teria o MPF atuado como fiscal da lei e opinado sobre a legalidade do pedido da ABRACE, garantindo, assim, o direito à saúde e à vida de vários associados, que se tornou a primeira associação a ter o direito de produzir remédios à base de maconha no Brasil.

Vê-se, portanto, que o argumento internacional foi buscado pelo MPF através da construção do seu discurso, expresso nas petições e no parecer. Também é possível observar a importância dada à questão de se realizar uma profunda análise da legislação internacional sobre direitos humanos, haja vista o ofício emitido ao Projeto de Extensão Universitária com vista à elaboração de um estudo técnico aprofundado sobre o tema. Vê-se que a mobilização das categorias jurídicas dos direitos humanos, reconhecidos na esfera internacional, deu maior poder de convencimento às manifestações do MPF. Assim, pode-se observar a importância do reforço no discurso jurídico com a inclusão dos direitos humanos nos pontos legitimadores do pedido.

Observa-se, por todo o exposto, a importância da legislação dos direitos humanos na esfera internacional e seu potencial de ser usado como ferramenta de transformação da realidade. $\mathrm{Na}$ análise, foi observada a influência dos dispositivos normativos internacionais quando da mobilização jurídica posta em marcha pelo MPF.

A problemática se torna mais complexa quando ocorre um déficit de eficácia de um direito já conquistado e previsto em lei, mas, mesmo assim, não é efetivo na vida das pessoas em geral. Isso se dá porque ocorre uma grande insegurança jurídica, mesmo com todos os dispositivos que impedem uma prática excludente e criminalizadora, o império da lei penal ainda se faz sentir como ameaça a todas as pessoas que precisam de derivados da maconha para tratamento de suas doenças. A segurança jurídica só é conquistada e o direito à saúde efetivado quando ocorre a mobilização das estruturas jurídicas por via da judicialização de demandas no poder judiciário. Se isto, por um lado, permite que seja possível a aplicação do direito de forma a resguardar o direito humano à vida; por outro, percebe-se que esse direito ainda não se encontra efetivado para muitas pessoas que não têm acesso ao judiciário.

Para tanto, é necessário que se afaste a legislação penal, bem como se regulamente de forma expressa o uso medicinal de derivados de cannabis de forma a afastar qualquer interpretação que não dê máxima prevalência aos direitos humanos. Também é claro que se torna necessário um trabalho político e cultural no sentido de tentativa de quebra de estigmas e de reforço à proteção dos direitos humanos, em específico de pacientes e seus familiares. Isso 

SOBRE DIREITOS HUMANOS NOS CASOS ENVOLVENDO O DIREITO

AO ACESSO À MACONHA MEDICINAL: UM ESTUDO A PARTIR DAS DEMANDAS JUDICIAIS ENVOLVENDO DERIVADOS DE CANNABIS NA

PARAÍBA

faz visualizar como, para além da lei e de sua previsão, o direito é um processo contínuo de construção e reconstrução, que passa pela luta dos movimentos sociais. Sendo assim, o direito é ferramenta, mas há a necessidade do componente político na luta contra a opressão e a negação dos direitos.

\section{CONCLUSÃO}

A importância da análise legal é perceptível no momento em que ela se constitui como importante ferramenta na luta pela emancipação dos grupos sociais. Para tanto, é necessário que o direito não seja visto como algo já dado e de natureza abstrata, mas como uma construção dos grupos sociais em suas lutas cotidianas, o que faz lembrar da reflexão inicial de Herrera Flores nos primeiros momentos desse estudo.

A questão perpassa vários ramos do direito e até outras ciências da área da saúde. No plano jurídico, os tratados internacionais vieram gradualmente sendo incorporados pelo direito nacional, de forma a assumir o status de supralegalidade ou de constitucionalidade, a depender da forma de sua aprovação. Foi evidenciada a aplicação dos tratados internacionais de direitos humanos a partir dos estudos de casos que envolvem a judicialização do direito ao acesso à maconha medicinal na Paraíba. Nesse ponto, percebe-se a importância dessas categorias jurídicas ao serem mobilizadas na defesa judicial de pacientes que demandam o judiciário em busca da efetividade de direitos humanos garantidos nos tratados internacionais dos quais o Brasil é signatário. A análise das peças judiciais incorporadas aos processos aqui analisados reforça a importância desses tratados quando da defesa judicial dos interesses dos pacientes usuários de derivados da cannabis na Paraíba. Um estudo de processos com expressa referência a esse arcabouço protetivo internacional à dignidade humana tem sua importância pois permite uma melhor compreensão de como essas normas podem impactar na garantia dos direitos fundamentais no Brasil. Também destaca-se a atuação do MPF, que recorreu aos tratados internacionais de direitos humanos como o ponto forte de sua argumentação em defesa dos direitos humanos, reforçando a importância do manejo dessa legislação protetiva internacional na práxis jurídica nacional.

Quando se vê a questão da luta pelo acesso à maconha medicinal no Brasil, observa-se como essa dinâmica é apresentada. Se, por um lado, existe substrato jurídico normativo para garantir o direito de acesso aos remédios à base de maconha por parte dos pacientes, conforme 
UMA ANÁLISE DA APLICAÇÃO DOS TRATADOS E CONVENÇÕES SOBRE DIREITOS HUMANOS NOS CASOS ENVOLVENDO O DIREITO

AO ACESSO À MACONHA MEDICINAL: UM ESTUDO A PARTIR DAS DEMANDAS JUDICIAIS ENVOLVENDO DERIVADOS DE CANNABIS NA

PARAÍBA

foi desenvolvido em tópico específico, por outro, na prática, apenas uma postura ativa por parte dos pacientes garantiu, em casos pontuais, a segurança jurídica no acesso ao direito à saúde, casos estes que foram submetidos ao judiciário através de estratégias de judicialização. Aqui fica evidenciado o dilema: tal direito, apesar de previsto, teve de ser construído a partir da atividade política, da cidadania ativa e de estratégias de judicialização de modo a garantir vitórias pontuais que assegurassem alguma segurança aos pacientes no que diz respeito ao seu tratamento. Logo, torna-se urgente a necessidade de reforma do ordenamento jurídico brasileiro, de forma a garantir, da melhor e mais eficaz maneira possível, os direitos expressos nos Tratados e Convenções sobre Direitos Humanos e na Carta Magna. Para tanto, são necessárias a regulamentação do uso da maconha para fins medicinais e a criação de políticas públicas que facilitem o acesso.

\section{REFERÊNCIAS}

ARAÚJO, Tarso. llegal: A vida não espera. Documentário. 90 min, 2014. Disponível em: https://www.youtube.com/watch?v=I-072T0enO4. Acesso em: 04 jun. 2015.

BRASIL. Constituição da República Federativa do Brasil de 1988. Encontrado em: http://www.planalto.gov.br/ccivil_03/Constituicao/Constituicao.htm. Acesso em: 10 mar. 2019.

BRASIL. Lei Ordinária $n^{\circ} 11.343$, de 23 de agosto de 2006. Lei de Tóxicos. Disponível em: http://www.planalto.gov.br/ccivil_03/_ato2004-2006/2006/lei/l11343.htm. Acesso em: 10 mar. 2019.

BRASIL. Decreto 54.216, de 27 de agosto de 1964. Convenção Única Sobre Estupefacientes. Disponível em: http://www2.camara.leg.br/legin/fed/decret/1960-1969/decreto-54216-27agosto-1964-394342-publicacaooriginal-1-pe.html. Acesso em: 12 set. 2018.

BRASIL. Decreto $N^{\circ} 79.388$, de 14 de março de 1977. Convenção sobre Substâncias Psicotrópicas. Disponível em: http://www2.camara.leg.br/legin/fed/decret/19701979/decreto-79388-14-marco-1977-428455-publicacaooriginal-1-pe.html. Acesso em: 12 set. 2018.

BRASIL. Decreto No 154, de 26 de junho de 1991. Convenção Contra o Tráfico llícito de Entorpecentes e Substâncias Psicotrópicas. Disponível em: http://www.planalto.gov.br/ccivil_03/Decreto/1990-1994/D0154.htm. Acesso em: 12 set. 2018.

BRASIL. Ministério da Saúde. Portaria SVS/MS no 344. Aprova o Regulamento Técnico sobre substâncias e medicamentos sujeitos a controle especial. Disponível em: 
UMA ANÁLISE DA APLICAÇÃO DOS TRATADOS E CONVENÇÕES SOBRE DIREITOS HUMANOS NOS CASOS ENVOLVENDO O DIREITO AO ACESSO À MACONHA MEDICINAL: UM ESTUDO A PARTIR DAS DEMANDAS JUDICIAIS ENVOLVENDO DERIVADOS DE CANNABIS NA PARAÍBA

http://bvsms.saude.gov.br/bvs/saudelegis/svs/1998/prt0344_12_05_1998_rep.html. Acesso em: 10 mar. 2019.

BRASIL. Decreto No 591, de 6 de julho de 1992. Atos Internacionais. Pacto Internacional sobre Direitos Econômicos, Sociais e Culturais. Promulgação. Disponível em: http://www.planalto.gov.br/ccivil_03/decreto/1990-1994/d0591.htm. Acesso em: 18 set. 2018.

BRASIL. Decreto $N^{\circ}$ 592, de 6 de julho de 1992. Pacto Internacional sobre Direitos Civis e Políticos. Disponível em: http://www2.camara.leg.br/legin/fed/decret/1992/decreto-592-6julho-1992-449004-publicacaooriginal-1-pe.html. Acesso em: 18 set. 2018.

BRASIL. Decreto No 678, de 6 de novembro de 1992. Promulga a Convenção Americana sobre Direitos Humanos (Pacto de São José da Costa Rica), de 22 de novembro de 1969. Disponível em: http://www.planalto.gov.br/ccivil_03/decreto/D0678.htm. Acesso em: 10 mar. 2019.

BRASIL. Ministério Público Federal. Procedimento Preparatório n 1.24.000.001421/2014-74. PFDC. Saúde. Canabidiol. Acesso à medicação. Reclassificação junto à ANVISA. Disponibilidade pelo SUS. Partes: representante: Sheila e outros; representados: ANVISA, 2014. Autuado 09/07/2014.

BRASIL. Justiça Federal. Ação Civil Pública nº 0802543-14.2014.4.05.8200, ajuizada em 31 de julho de 2014 ( $1^{\text {a }}$ Vara Federal). In: BRASIL. Ministério Público Federal. Procedimento Preparatório n 1.24.000.001421/2014-74. PFDC. Saúde. Canabidiol. Acesso à medicação. Reclassificação junto à ANVISA. Disponibilidade pelo SUS. Partes: representante: Sheila e outros; representados: ANVISA, 2014. Autuado 09/07/2014.

BRASIL. Justiça Federal. Ação Civil Pública n 0802271-83.2015.4.05.8200, ajuizada em 15 de

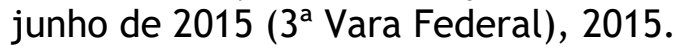

BRASIL. Manifestação nº 3201/2017/MPF/PRPB/GAB-JGBS. Justiça Federal. Processo 080033382.2017.4.05.8200. Autora: ABRACE. In: BRASIL. Ministério Público Federal. Procedimento Preparatório n 1.24.000.001421/2014-74. PFDC. Saúde. Canabidiol. Acesso à medicação. Reclassificação junto à ANVISA. Disponibilidade pelo SUS. Partes: representante: Sheila e outros; representados: ANVISA, 2014. Autuado 09/07/2014.

BOBBIO, Norberto. A era dos direitos. Tradução de Carlos Nelson Coutinho. Rio de Janeiro: Elsevier, 2004.

BOITEUX, Luciana; WIECKO, Ela de Castilho. Tráfico de Drogas e Constituição. Um estudo jurídico-social do tipo do art. 33 da Lei de Drogas diante dos princípios constitucionais-penais, 2009.

BOITEUX, Luciana. Controle penal sobre as drogas ilícitas: o impacto do proibicionismo no sistema penal e na sociedade. Programa de Pós-Graduação em Direito, Faculdade de Direito, Universidade de São Paulo. Tese de Doutorado. São Paulo, 2006, 237 f. 
UMA ANÁLISE DA APLICAÇÃO DOS TRATADOS E CONVENÇÕES SOBRE DIREITOS HUMANOS NOS CASOS ENVOLVENDO O DIREITO

AO ACESSO À MACONHA MEDICINAL: UM ESTUDO A PARTIR DAS DEMANDAS JUDICIAIS ENVOLVENDO DERIVADOS DE CANNABIS NA

BOITEUX, Luciana; PIRES, Thula Rafaela de Oliveira; BATISTA, Vanessa Oliveira. Direitos Humanos. Convocação 01/2007. Série pensando o direito $N^{\circ} 5 / 2009$ - versão publicação. Ministério da Justiça, 2009.

BOITEUX, Luciana et al. DIREITOS HUMANOS E CONVENÇÕES INTERNACIONAIS DE DROGAS: Em Busca de uma Razão Humanitária nas Leis de Drogas. In: Drogas e direitos humanos: reflexões em tempos de guerra às drogas [recurso eletrônico] / Marcelo Dalla Vecchia... [et al.] organizadores. - 1. ed. - Porto Alegre: Rede UNIDA, 2017.

CRESWELL, John. W. Projeto de pesquisa: métodos qualitativo, quantitativo e misto. Porto Alegre: Artmed, 2007.

CARDOSO, Henrique Ribeiro \& MAYER, Maria Luiza Pereira de Alencar. Direitos Sociais, Saúde Pública no Brasil, Precarização dos Vínculos Funcionais e Reflexos para o Usuário do Sistema Único de Saúde-SUS. Prim@ Facie-Direito, História e Política, v. 13, n. 25, p.01-47, 2014.

CARVALHO, Salo de. A política criminal de drogas no Brasil: estudo criminológico e dogmático. 6 ed. São Paulo: Saraiva 2013.

FOUCAULT, Michel. Em defesa da sociedade: curso no Collège de France (1975-1976). São Paulo: Martins Fontes, 1999.

FOUCAULT, Michel. A Verdade e as Formas Jurídicas. 3. ed. Rio de Janeiro: Nau, 2009.

FOUCAULT, Michel. A ordem do discurso: aula inaugural no Collège France pronunciada em 2 de dezembro de 1970. São Paulo: Edições Loyola, 2013.

FOUCAULT, Michel. História da sexualidade I: A vontade de saber. São Paulo: Paz e Terra, 2014.

FOUCAULT, Michel. Os Anormais: Curso no Collège de France (1974-1975). São Paulo: Martins Fontes, 2002.

HERRERA, Joaquín Flores. A (re)invenção dos direitos humanos. Florianópolis: Fundação Boiteux, 2009.

LIPPI, Camila Soares. O discurso das drogas construído pelo direito internacional. Revista de Direito Internacional, v. 10, n. 2, p.53-65, 2014.

MATTOS, Paulo E. Orlandi. Modelos internacionais de regulamentação do uso medicinal da cannabis. In: Drogas no Brasil: entre a saúde e a justiça: proximidades e opiniões / Vilma Bokany (org.). São Paulo: Editora Fundação Perseu Abramo, 2015.

MAYER, Maria Luiza Pereira de Alencar et al. Direitos humanos, econômicos, sociais e culturais. Prim@ Facie-Direito, História e Política, v. 5, n. 8, 2006.

ROSE, Nikolas. A política da própria vida: biomedicina, poder e subjetividade no século XXI. São Paulo: Paulus, 2013. 
UMA ANÁLISE DA APLICAÇÃO DOS TRATADOS E CONVENÇÕES SOBRE DIREITOS HUMANOS NOS CASOS ENVOLVENDO O DIREITO

AO ACESSO À MACONHA MEDICINAL: UM ESTUDO A PARTIR DAS DEMANDAS JUDICIAIS ENVOLVENDO DERIVADOS DE CANNABIS NA

PARAÍBA

LUCIANO NASCIMENTO SILVA LUCAS LOPES OLIVEIRA

SARLET, Ingo Wolfgang; FIGUEIREDO, Mariana Filchtiner. Algumas considerações sobre o direito fundamental à proteção e promoção da saúde aos 20 anos da Constituição Federal de 1988. Revista de Direito do Consumidor, v. 67, p.125-172, 2008.

SARLET, Ingo Wolfgang. A titularidade simultaneamente individual e transindividual dos direitos sociais analisada à luz do exemplo do direito à proteção e promoção da saúde. Revista Brasileira de Direitos Fundamentais \& Justiça, 4(10), 205-228, 2010.

https://doi.org/10.30899/dfj.v4i10.449

OLIVEIRA, Lucas Lopes; RIBEIRO, Luziana Ramalho. DISCURSOS MÉDICOS E JURÍDICOS SOBRE MACONHA NA PARAÍBA: a judicialização do direito ao acesso à maconha medicinal. Revista de Estudos Empíricos em Direito, v. 4, n. 2, 2017.

OLIVEIRA, Lucas Lopes. Discursos médicos e jurídicos sobre maconha no Brasil e na Paraíba: os contradiscursos no debate sobre as políticas de drogas à luz dos direitos humanos. (Dissertação de Mestrado). Programa de Pós-Graduação em Direitos Humanos, Cidadania e Políticas Públicas PPGDH/UFPB, 2016.

ONU. Declaração Universal dos Direitos Humanos. Disponível em: https://www.unicef.org/brazil/pt/resources_10133.htm. Acesso em: 10 mar. 2019.

PIOVESAN, Flávia. Direitos humanos e o direito constitucional internacional. São Paulo: Saraiva, 2013.

Recebido em: 15.04.2019 / Aprovado em: 10.07.2020 / Publicado em: 22.07.2020

\section{COMO FAZER REFERÊNCIA AO ARTIGO (ABNT):}

SILVA, Luciano Nascimento; OLIVEIRA, Lucas Lopes. Uma análise da aplicação dos tratados e convenções sobre direitos humanos nos casos envolvendo o direito ao acesso à maconha medicinal: um estudo a partir das demandas judiciais envolvendo derivados de cannabis na Paraíba. Revista Eletrônica do Curso de Direito da UFSM, Santa Maria, RS, v. 15, n. 2, e37744, maio/ago. 2020. ISSN 1981-3694. DOI:

http://dx.doi.org/10.5902/1981369437744. Disponível em:

https://periodicos.ufsm.br/revistadireito/article/view/37744. Acesso em: dia mês. ano.

Direitos autorais 2020 Revista Eletrônica do Curso de Direito da UFSM

Editores responsáveis: Rafael Santos de Oliveira e Angela Araujo da Silveira Espindola

Esta obra está licenciada com uma Licença Creative Commons Atribuição-NãoComercial-SemDerivações 4.0 Internacional.

\section{SOBRE OS/AS AUTORES/AS}

\section{LUCIANO NASCIMENTO SILVA}

Pós-Doutor em Sociologia do Direito pela Facoltà di Giurisprudenza dell 'Università del Salento, Itália (2014-16). Professor Ajunto no CCJ/UEPB. Professor Colaborador Permanente no PPGCJ/CCJ/UFPB e PPGDH/NCDH/UFPB. Líder do Grupo NUPOD Núcleo para Pesquisa dos Observadores do Direito - DGP/CNPq.

LUCAS LOPES OLIVEIRA

Mestre em Direitos Humanos, Cidadania e Políticas Públicas (UFPB). Doutorando em Ciências Jurídicas (UFPB). 